\title{
Research and analysis of harmful road emissions from a two-wheel vehicle engine in laboratory conditions
}

\begin{abstract}
The subject of this article is the identification of engine exhaust emissions of two-wheel vehicles under laboratory conditions. For this purpose, analysis of road and time emission of gaseous compounds: $\mathrm{HC}, \mathrm{CO}, \mathrm{CO}_{2}, \mathrm{NO}_{x}$ from a motorcycle equipped with an engine with a displacement volume of $0.7 \mathrm{dm}^{3}$ and a maximum power of $55 \mathrm{~kW}$ was made. The tests were performed on a dynamometer station designed for testing two-wheel vehicles. The speed characteristic was taken from the European type approval test WMTC, consisting of three parts. Each of these parts lasted 600 seconds and was characterized by a different maximum vehicle speed value. The mobile AXION R/S apparatus part of the PEMS device group was used in the research. What is more, the exhaust emissions results were referred to the values listed by the exhaust emission standard met by the tested vehicle (Euro 4 standard). Laboratory tests presented in the article are only intended as a basis for further research, which includes exhaust emission tests from two-wheel vehicles in real operating conditions.
\end{abstract}

Key words: two-wheeler, motorcycle exhaust emissions, WMTC test

\section{Introduction}

One of the most important sources of greenhouse gas emission is combustion engines used in transport, heavy machinery, and other equipment. Another aspect tightly related to the operation of combustion engines is exhaust emissions. Today, we know that exhaust components such as $\mathrm{CO}, \mathrm{HC}, \mathrm{NO}_{\mathrm{x}}$, and $\mathrm{PM}$ (as a mass and particle number $\mathrm{PN}$ ) are hazardous to human health. Therefore very important are action lead to reduction exhaust emission from all type of vehicles also two-wheels.

Economic development, and hence the increase in the wealth of the population of all world agglomerations, leads to an increasing share of road transport, in which, apart from cars and trucks, including the two-wheelers vehicle group. This group makes it possible for people to meet everyday transport needs, especially in Africa and Asia, where the share of motorcycles and scooters accounts for $70 \%$ of the entire fleet of road vehicles [8]. Asia has the highest number of motorcycles, especially mopeds which are very important transportation tool. The motorcycles sale in Asia is still significant in comparing to the other areas of the world (Fig. 1). In India alone, in one year (2017) the number of sold two-wheeled vehicles amounted to almost 18 million units, which gives a result of 48 thousand vehicles a day. In Europe, the number of newly registered motorcycles and mopeds is dominated by Germany, France and Italy (as of 2016) [11]. Motorcycles emit significant air pollutants. For example, motorcycles with about $54 \%$ of the total vehicle population in Jakarta, Indonesia, emit in 1998 to more than $20 \%$ of PM10, and $\mathrm{CO}$ and $40 \%$ of HC. A similar is in Hanoi, Vietnam, where motorcycles contributed about $54 \%$ of $\mathrm{CO}$ and $\mathrm{HC}$ and $43 \%$ dust [12]. The effect of that, according to the WHO (World Health Organization), each year there are around 600,000 premature deaths from diseases directly related to air pollution in India [3]. The same problem of motorcycle emissions are taking place in many Asian cities. Therefore it is clear that priority must be given to reduce pollutions from motorcycles.

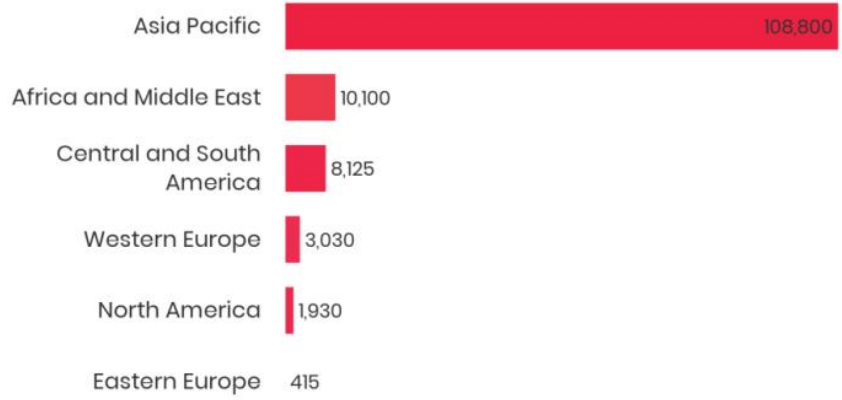

Fig. 1. Projected motorcycles sales worldwide (in thousand units) in 2018 by region [15]

The advantages resulting from the use of two-wheelers (avoiding road congestion, no problem finding a parking space and the ease of obtaining a license) cause a continuous increase in the share of this vehicle category, in particular in Asian countries. This fact lead to many research and development centers performing intensive research work on the assessment of exhaust emission from this type of vehicles. This is confirmed by numerous publications, in particular by scientists from Indonesia and India, where due to the lack of a developed public transport network twowheeled vehicles accounts for $80 \%$ of private transport sector [9].

The issue of emissivity is connected with increased expenditures of legislators and authorities of all highly developed countries to improve air quality in urban centers. Therefore, increasingly restrictive emission standards for motorcycles are being introduced. Figure 2 presents the development of emission standards in Europe, while Fig. 
3 presents the development of exhaust emissions limits, which are more restrictive in next steps. The proposal of Euro 5 limits which will introduce in 2020 most likely will be more restrict than Euro 5. Moreover it is likely that in Euro 5 standards the new methods of measurement will be apply (cycles or real driving emissions measurement). However, many scientific papers [4-7] have shown that adopted type approval tests, such as WMTC (World Motorcycles Test Cycle) do not fully reproduce the real operating conditions of these engines, and thus also their emissions. Therefore, laboratory tests using the current WMTC test presented in this article are only the basis for further work of au-thors, which are exhaust emission tests from two-wheelers in real operating conditions. They were necessary to get to know the parameters of the combustion engine operation.

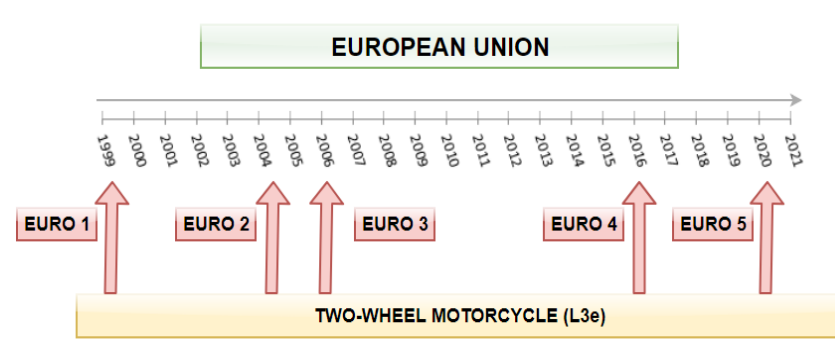

Fig. 2. History of exhaust emission standards for two-wheeled vehicles in Europe [10]

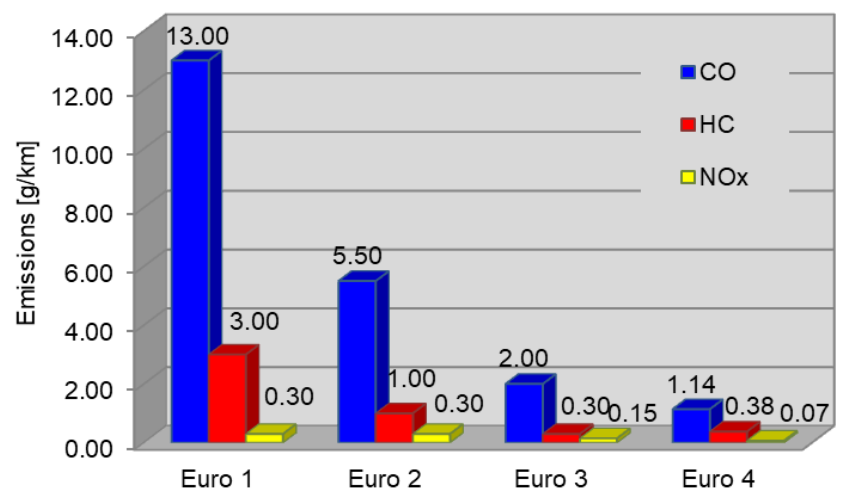

Fig. 3. The exhaust emission limits for motorcycles (category L3e)

The amending regulation „Commission Regulation of European Union 2016/646 on type-approval of motor vehicle include test procedures for RDE (Real Driving Emissions) for Euro 6d homologation LDV (Light Duty Vehicles) vehicles. As of today's date there are not similar regulation for motorcycles. Therefore, it is to be expected that in the coming years the methodology of testing powered twowheeler-applications will remain unchanged.

\section{Research metodology}

\subsection{Research object}

The test object was a motorcycle type approved in accordance with the Euro 4 standard. The vehicle was equipped with a four-stroke engine with a displacement volume of $0.7 \mathrm{dm}^{3}$ and a maximum power of $55 \mathrm{~kW}$. The motorcycle was produced in 2017. Before the start of the test, its mileage was $740 \mathrm{~km}$. Table 1 presents the technical parameters of the motorcycle. The test vehicle was equipped with a three-way catalytic reactor.

Table 1. Test motorcycle operating parameters

\begin{tabular}{|l|c|}
\hline Engine type & $\begin{array}{c}2 \text { cylinders, liquid-cooled 4-stroke, } \\
\text { DOHC, 4-valve }\end{array}$ \\
\hline Displacement & $0.7 \mathrm{dm}^{3}$ \\
\hline Maximum power & $55 \mathrm{~kW} / 9000 \mathrm{rpm}$ \\
\hline Maximum torque & $68 \mathrm{Nm} / 6500 \mathrm{rpm}$ \\
\hline $\begin{array}{l}\text { Cylinder diameter/piston } \\
\text { stroke }\end{array}$ & $80.0 \mathrm{~mm} \times 68.6 \mathrm{~mm}$ \\
\hline Compression ratio & $11.5: 1$ \\
\hline Lubrication system & wet oil sump \\
\hline
\end{tabular}

\subsection{Chassis dynamometer}

The tests were performed on a single-cylinder chassis dynamometer designed for testing two-wheeled vehicles. The INTERNAL 70 motorcycle test bench was manufactured by SOFT-ENGINE, and its specification is presented in Table 2. The stand enables the reading of the vehicle's load parameters (instantaneous power, torque, speed, acceleration) as well as the distance traveled.

Table 2. Technical specifications of the dynamometer station [14]

\begin{tabular}{|l|c|}
\hline Dynamometr & Inertial \\
\hline Maximum received power & $59 \mathrm{~kW}(80 \mathrm{HP})$ \\
\hline Maximum received velocity & $180 \mathrm{~km} / \mathrm{h}$ \\
\hline Dimensions: length /width / height & $1900 / 800 / 4200 \mathrm{~mm}$ \\
\hline Own weight & $450 \mathrm{~kg}$ \\
\hline Software & INERTIAL 3.0 \\
\hline
\end{tabular}

\subsection{Measurement equipment}

Measurement of harmful compounds in laboratory conditions was possible thanks to the AxionR/S+ mobile apparatus belonging to the PEMS (Portable Emissions Measurement System) group (Fig. 4). The device allows to measure emissions of harmful and toxic compounds, both gaseous: hydrocarbons (HC), carbon monoxide (CO), carbon dioxide $\left(\mathrm{CO}_{2}\right)$, nitrous oxide (NO) as well as solid particles. Technical data of the apparatus is presented in Table 3, while the test object with the measuring setup on the dynamometer stand is shown in Fig. 5. Electrochemical analyzers are used to determine $\mathrm{NO}$ and $\mathrm{O}_{2}$. The concentration of the first three of these compounds is measured by an NDIR (Nondispersive Infrared Sensor) non-dispersive analyzer. The PM measurement method uses a Laser Scatter based method.

In addition, the manufacturer equipped the device with a meteorological station, a GPS and a module enabling registration of data from the on-board vehicle diagnostic system (OBD). Measurement and data acquisition was done at a 
frequency of $1 \mathrm{~Hz}$. Corrections are made to the obtained results from the recorded data, and then the road/unit emissions of the tested exhaust gases are calculated. Moreover the AxionR/S allows measurement and recording of vehicle and engine data: vehicle speed, acceleration, engine speed, intake air temperature, manifold air pressure.

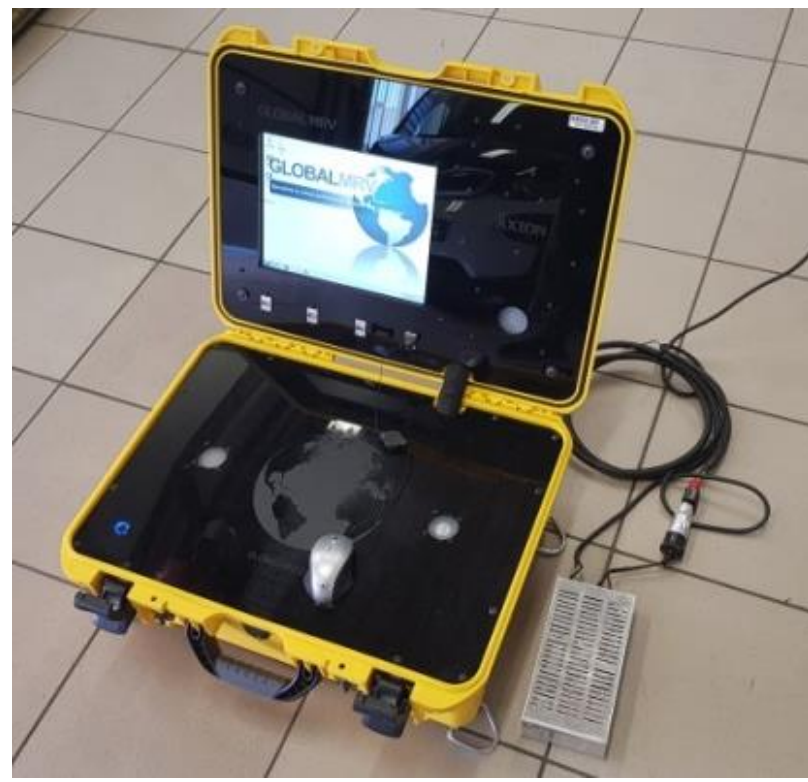

Fig. 4. The view of AxionR/S+

Table 3. AxionR/S+ device technical data [13]

\begin{tabular}{|c|c|c|c|c|}
\hline Gas & $\begin{array}{c}\text { Mesaure- } \\
\text { ment range }\end{array}$ & Accuracy & Resolution & $\begin{array}{c}\text { Type of } \\
\text { mesaure- } \\
\text { saure- } \\
\text { ment }\end{array}$ \\
\hline $\mathrm{HC}$ & $0-4000 \mathrm{ppm}$ & $\begin{array}{c} \pm 8 \mathrm{ppm} \text { abs. or } \\
\pm 3 \% \text { rel. }\end{array}$ & $1 \mathrm{ppm}$ & NDIR \\
\hline $\mathrm{CO}$ & $0-10 \%$ & $\begin{array}{c} \pm 0.02 \% \text { abs. or } \\
\pm 3 \% \text { rel. }\end{array}$ & $\begin{array}{c}0.001 \mathrm{vol} . \\
\%\end{array}$ & NDIR \\
\hline $\mathrm{CO}_{2}$ & $0-16 \%$ & $\begin{array}{c} \pm 0.3 \% \text { abs. or } \\
\pm 4 \% \text { rel. }\end{array}$ & $0.01 \mathrm{vol} \%$ & NDIR \\
\hline $\mathrm{NO}^{2} \%-4000 \mathrm{ppm}$ & $\begin{array}{c} \pm 25 \mathrm{ppm} \text { abs. } \\
\text { or } \pm 3 \% \text { rel. }\end{array}$ & $1 \mathrm{ppm}$ & E-chem \\
\hline $\mathrm{O}_{2}$ & $0-25 \%$ & $\begin{array}{c} \pm 0.1 \% \mathrm{ppm} \\
\text { abs. or } \pm 3 \% \text { rel. }\end{array}$ & $0.01 \mathrm{vol.} \%$ & E-chem \\
\hline $\mathrm{PM}$ & $\begin{array}{c}0 \mathrm{mg} / \mathrm{m}^{3} \text { to } \\
300 \mathrm{mg} / \mathrm{m}^{3}\end{array}$ & $\pm 2 \%$ & $0.01 \mathrm{mg} / \mathrm{m}^{3}$ & $\begin{array}{c}\text { Laser } \\
\text { scatter }\end{array}$ \\
\hline
\end{tabular}

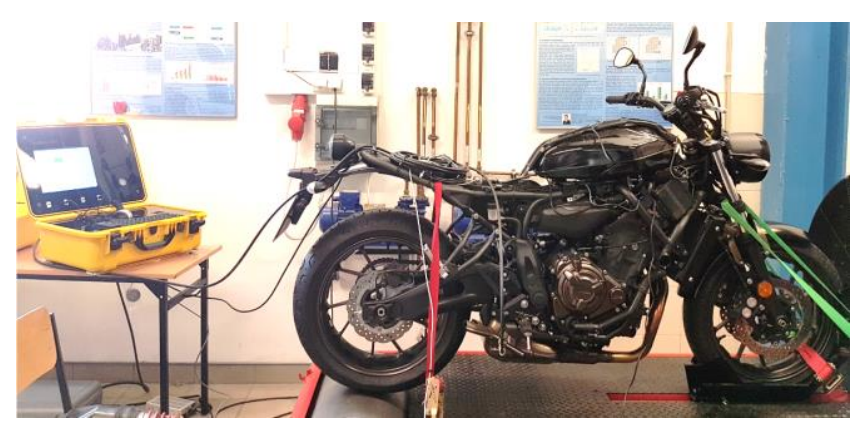

Fig. 5. Picture of the tested motorcycle along with the measuring apparatus on the designated dynamometer

The device is one of the most modern measuring instruments, housing analyzers for measuring both gaseous and solid compounds in a housing with a total weight of only $18 \mathrm{~kg}$. The main advantages of the device: its low weight and small size dimensions make it possible to use to test the emissions of all legally limited toxic compounds from two-wheeled vehicles in real operating conditions.

What's more, the device also measures the mass emission of solid particles, which legislators are planning to limit through legislation with the Euro 5 standard in 2020. The review of available literature showed the lack of such tests, and the only item [2] describing exhaust emission tests of two-wheeled vehicles in real conditions of operation was based on the measurements made with the use of a dedicated passenger car, whose dimensions and weight made tests possible only on a larger motorcycle unit.

\subsection{WMTC test}

The amount of two-wheeler vehicles in urban regions grow very fast, especially in Asia region. This underlines the need for improving pollutian control strategies for motorcycles and mopeds. Therefore, numerous test cycles for chassis dynamometer are available. Test cycles have been developed by real conditions data that shall not be based on fixed legislative driving standards, but reflect local real driving conditions. A driving cycles usually are a speed-time profile, sometimes with the gear information, for a definite length of time for a specific type of vehicle. Cycles represent different driving patterns and modes such as acceleration, deceleration, cruising and idling modes.

The World Motorcycle Test Cycle (WMTC) is a driving cycles used to measure fuel consumption and emissions in motorcycles. The methods of WMTC cycle are set up as part of the Global Technical Regulation established under the United Nations' World Forum for Harmonisation of Vehicle Regulations.

The speed curve was a reflection of the speed characteristic of the harmonized WMTC type approval test, consisting of three phases (Fig. 6). Each of them lasted 600 seconds and was characterized by a different maximum value of the speed. The maximum speeds of the individual test phases are respectively: 50,94 and $125 \mathrm{~km} / \mathrm{h}$, while the average: $24.4,54.7,94.4 \mathrm{~km} / \mathrm{h}$. The total distance in the test is $28,912 \mathrm{~m}$, and the individual phases: 4065, 9111 and $15,736 \mathrm{~m}$.

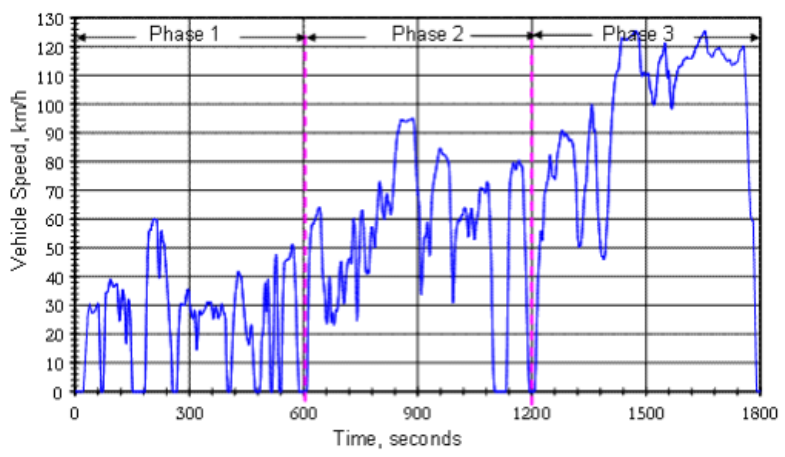

Fig. 6. WMTC test cycle speed curve [11]

\section{Analysis and results}

\subsection{Engine operating parameters analysis}

The data obtained during the WMTC test on the chassis dynamometer allowed to obtain the engine operation time 
share characteristics. This is a graphical representation of the share of operating time (in relation to the duration of the entire test) for individual engine speed ranges and its fuel consumption. Fuel consumption depends on carbon dioxide emissions and load, hence these terms will be used interchangeably. Based on the obtained results, it was found that the motorcycle engine worked most often in rotational speed range of 2000-4000 rpm and fuel consumption in the range of $0-0.75 \mathrm{~g} / \mathrm{s}$ (Fig. 7). The share of operating time in this range amounted to almost $62 \%$. This is also confirmed by the average speed and average fuel consumption values, which amounted to $3220 \mathrm{rpm}$ and $0.54 \mathrm{~g} / \mathrm{s}$, respectively. A significant share of operating time was also found for the speed range of 1000-1500 rpm and for fuel consumption in the range of $0-0.25 \mathrm{~g} / \mathrm{s}$, which accounts for $12 \%$ of its operation.

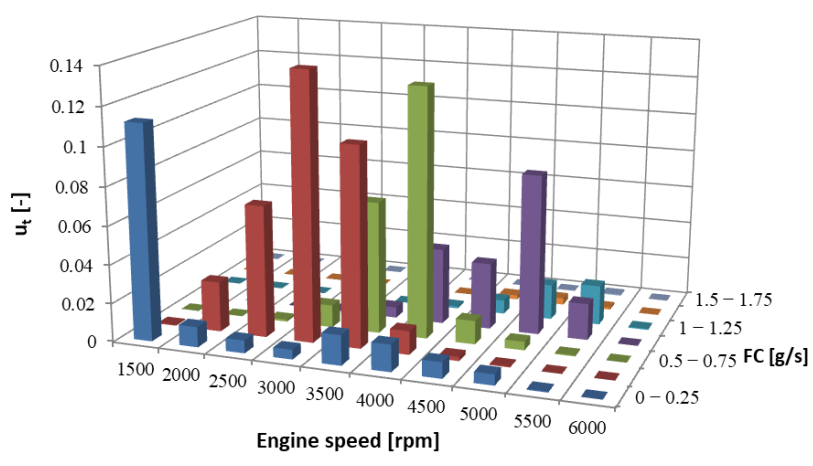

Fig. 7. Operating time density for different speed ranges and fuel consumption values

\subsection{Analysis of the engine ecological indicators}

The characteristics of the environmental performance of the tested vehicle, as in the case of the characteristics of the engine operation time density, are presented as a function of the engine rotational speed and the instantaneous engine load associated with fuel consumption. The influence of the engine operating parameters on its ecological indicators was determined for each of the substances limited by the Euro 4: $\mathrm{CO}, \mathrm{HC}$, and $\mathrm{NO}_{\mathrm{x}}$. Due to the close relation between the carbon dioxide emissions and the fuel consumed, the characteristics for this exhaust component were omitted.

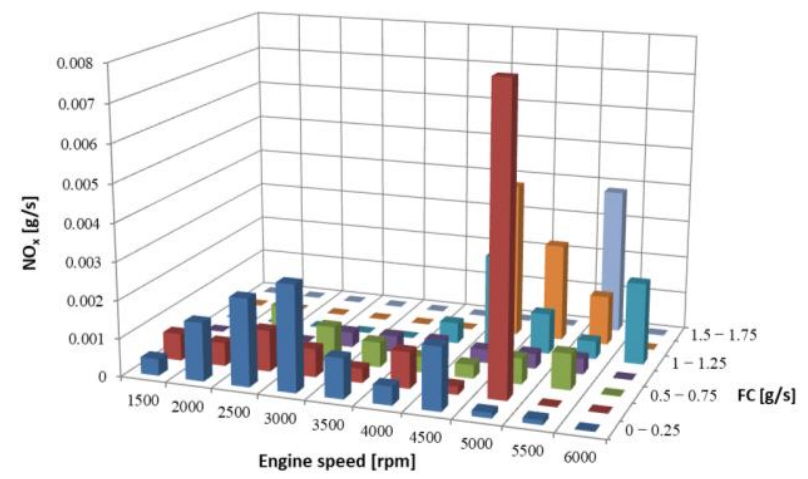

Fig. 8. $\mathrm{NO}_{\mathrm{x}}$ emission per second as a function of engine speed and fuel consumption ranges
The time emission of $\mathrm{NO}_{\mathrm{x}}$ depends both on engine speed and engine load (Fig. 8). For the tested motorcycle, the maximum value of $\mathrm{NO}_{\mathrm{x}}$ emissions $(0.008 \mathrm{~g} / \mathrm{s})$ was registered for the speed range 4500-5000 rpm and the load of $0.25-0.5 \mathrm{~g} / \mathrm{s}$ of fuel consumed. The average emission for this compound was $0.0067 \mathrm{~g} / \mathrm{s}$.

Although $\mathrm{NO}_{\mathrm{x}}$ emission was determined for a wide range of engine speeds and loads, the highest values were registered for the high rotational speeds range of 4000$5500 \mathrm{rpm}$ and fuel consumption of $0.25-0.5 \mathrm{~g} / \mathrm{s}$. High engine speeds generate a higher temperature in the cylinder, which directly favors the formation of nitrogen oxides.

The characteristics of $\mathrm{CO}_{2}$ emissions as a function of rotational speed and load are shown in figure 9. This figure indicates that the highest emission values were in the high engine speed range from 4500-5000 rpm and fuel consumption in the range $0.5-1.75 \mathrm{~g} / \mathrm{s}$. The high engine speed, and hence the high doses of fuel supplied, cause global and local oxygen deficiencies, which is closely related to the formation of $\mathrm{CO}_{2}$. What is more, their formation was also influenced by the high temperature in the cylinder, which was conducive to $\mathrm{CO}_{2}$ dissociation. The highest value, $0.05 \mathrm{~g} / \mathrm{s}$, was recorded for speeds in the range of $5000-5500 \mathrm{rpm}$ and fuel consumption of $1.5-$ $1.75 \mathrm{~g} / \mathrm{s}$.

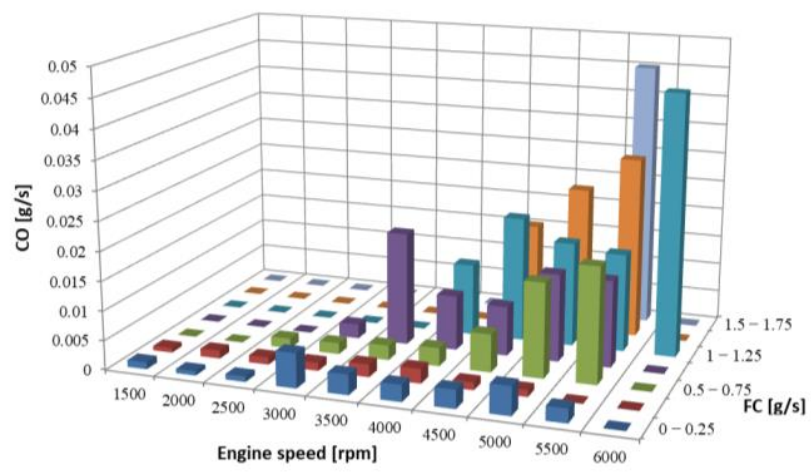

Fig. 9. CO emission per second as a function of engine speed and fuel consumption ranges

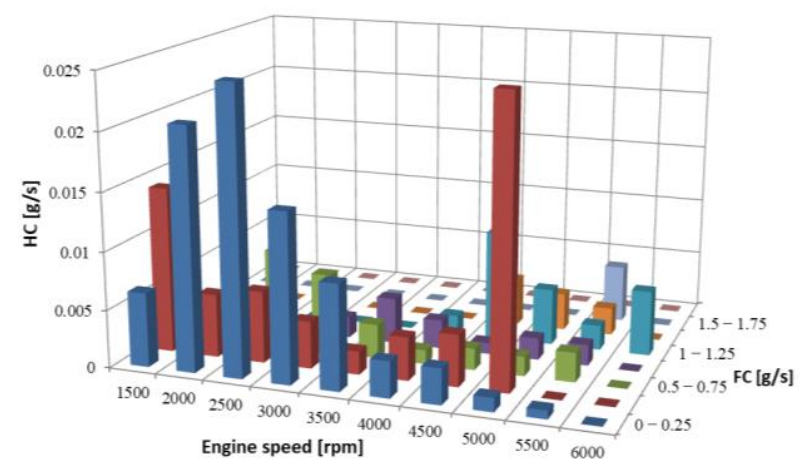

Fig. 10. HC emission per second as a function of engine speed and fuel consumption ranges

The characteristics of the HC emission per second as a function of engine rotational speed and fuel consumption (Fig. 10) showed that the largest hydrocarbon emission 
values were in the range of low loads and average rotational speeds of 1000-2500 rpm with fuel consumption in the range of $0-0.5 \mathrm{~g} / \mathrm{s}$.

Another significant range of the existing $\mathrm{HC}$ emission values is for the rotational speeds of $4000-5500 \mathrm{rpm}$ and a load of $0.25-1.75 \mathrm{~g} / \mathrm{s}$. In this value range the highest $\mathrm{HC}$ emission value was recorded, which amounted to $0.005 \mathrm{~g} / \mathrm{s}$. The reason for this is the fact that at high rotational speeds the injected fuel dose did not mix thoroughly resulting in incomplete combustion.

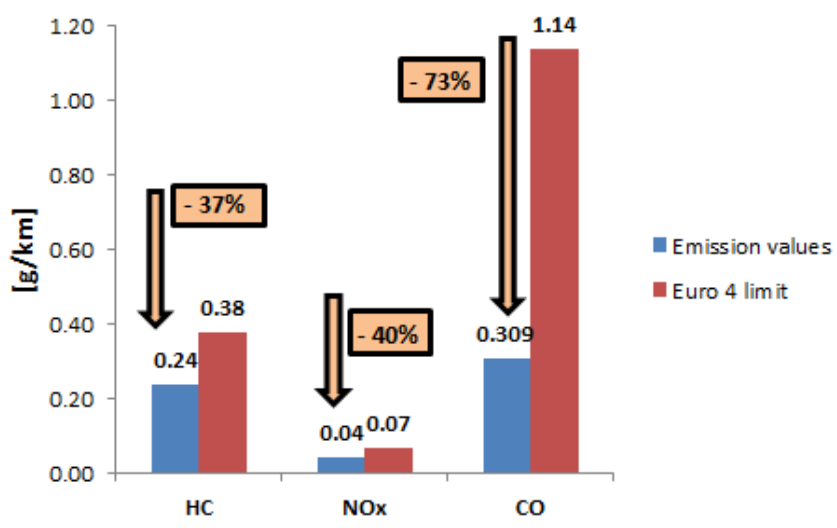

Fig. 11 Comparison of the determined road emission with the Euro 4 emission standard

Using the determined mass emissions of individual gas compounds and the distance traveled during the whole test, the road emission of each compound was calculated. The obtained emission values were compared with the admissible values specified for the Euro 4 standard (Fig. 11). The set emission value limits were not exceeded. For CO, an emission value was $73 \%$ lower than the limit value, for $\mathrm{HC}$ and $\mathrm{NO}_{\mathrm{x}}$ it was lower by almost $40 \%$, which was associated with high efficiency of the engine exhaust aftertreatment system, which comprised of a three-way catalytic reactor (allowing oxidation of carbon monoxide and hydrocarbons at simultaneous reduction of nitrogen oxides). Meeting the emission standards was also the result of the fact that the vehicle was still fairly new.

\section{Bibliography}

[1] Asian Development Bank. Integrated Vehicle Emission Reduction Strategy for Greater Jakarta, Indonesia, 2002.

[2] HIESMAYR, J., SCHMIDT, S., HAUSBERGER, S., KIRCHBERGER, R. et al. Results, assessment and legislative relevance of RDE and fuel consumption measurements of two-wheeler-applications. SAE International. 2017, 32(0042).

[3] ICCT, The International Council on Clean Transportation, Where we work/India, http://www.theicct.org/india.

[4] MARTINI, G., MANFREDI, U., DE GENNARO, M. Gaseous emissions from Euro 3 motorcycles and Euro 5 passenger cars measured over different driving cycles. SAE International. 2013, 01(2619).

\section{Conclusions}

The tests performed on a two-wheel vehicle chassis dynamometer and analysis of their results allowed to formulate conclusions regarding the work indicators and ecological characteristics of the test vehicle. The analysis did not find any exceedances of the emission limit imposed by the legislators, which confirms the validity of the current directions of motorcycle engines development. The main development tendency (as in the case of car engines) is to meet ever more stringent emission standards by using engine exhaust aftertreatment systems. The test vehicle was equipped with a three-way catalytic reactor. The fact that both the vehicle and the aftertreatment system were not deteriorated through heavy exploitation lead to a positive impact on the final road emission results for all harmful compounds limited by the Euro 4 standard.

The WMTC test is characterized by high engine speed variability, which is extremely difficult to accurately reproduce on a chassis dynamometer. Differences of several dozen percent between the final obtained results and the emission limits prove that the vehicle meets the established standards at the lower end of their range. This is very advantageous in the aspect of long-term operation of the engine and the exhaust aftertreatment systems, because over time their wear will adversely affect the engine's ecological indicators.

Numerous studies have shown that emissions in real operating conditions are significantly different from those obtained under laboratory conditions when using type approval tests (this is described in more detail in the introduction). Therefore, the research done in this article is the basis for further research by the authors, which will be focused on measurements of engine operating parameters and emissions in real driving conditions. The measurements will be made on the same test vehicle using the same measuring apparatus, in order to enable a reliable comparison of the obtained results. The development of measurement technology for the emission of toxic and harmful components (lower weight and dimensions of the exhaust gas analyzers, and the ability to measure gaseous compounds and particulates using only one device) makes it possible to test even two-wheeled vehicles in real operating conditions. Such research is new, both on a national and global scale.
[5] SALEH, W., KUMAR, R., KIRBY, H., KUMAR, P. Real world driving cycle for motorcycles in Edinburg. Transportation Research. 2009, 14, 326-333.

[6] TONG, H.Y., TUNG, H.D., HUNG, W.T., NGUYEN, H.V. Development of driving cycles for motorcycles and lightduty vehicles in Vietnam. Atmospheric Environment. 2011, 45, 5191-5199.

[7] TSAI, J.H., CHIANG, H.L., HSU, Y.C., PENG, B.J et al. Development of a local real world driving cycle for motorcycles for emission factor measurements. Atmospheric Environment. 2005, 39, 6631-6641.

[8] TSAI, J.H., HUNAG, P.H., CHIANG, H.L. Air pollutants and toxic emissions of various mileage motorcycles for ECE driving cycles. Atmospheric Environment. 2017, 153, 126134. 
[9] YUDIOSON, A., REKSOWARDOJO, I.K., SULAEMAN, A., Motorcycle emission profiles in Bandung City, Indonesia. SAE International. 2017, 32(0076).

[10] Worldwide Emissions Standards. Passenger Cars \& Light Duty Vehicles. Delphi brochure 2016/2017.

[11] www.asphaltandrubber.com

Natalia Szymlet, MEng. - Faculty of Machines and Transport, Poznan University of Technology.

e-mail: Natalia.R.Szymlet@doctorate.put.poznan.pl

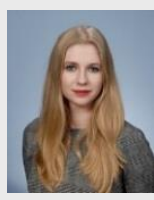

[12] www. ec.europa.eu

[13] www. globalmrv.com

[14] www.soft-engine.org

[15] statistica.com

Łukasz Rymaniak, DEng. - Faculty of Machines and Transport, Poznan University of Technology.

e-mail:Lukasz.Rymaniak@put.poznan.pl

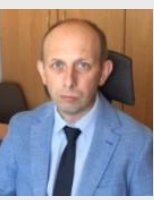

Maciej Siedlecki, MEng. - Faculty of Machines and Transport, Poznan University of Technology. and Transport, Poznan University of Technology.

e-mail: Piotr.Lijewski@put.poznan.pl

e-mail: Maciej.S.Siedlecki@doctorate.put.poznan.pl

Barbara Sokolnicka, MEng. - Faculty of Machines,

Transport at Poznan University of Technology.

e-mail:Barbara.D.Sokolnicka@doctorate.put. poznan.pl

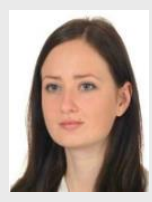

